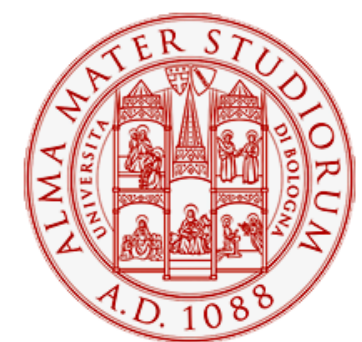

Alma Mater Studiorum - Università di Bologna DEPARTMENT OF ECONOMICS

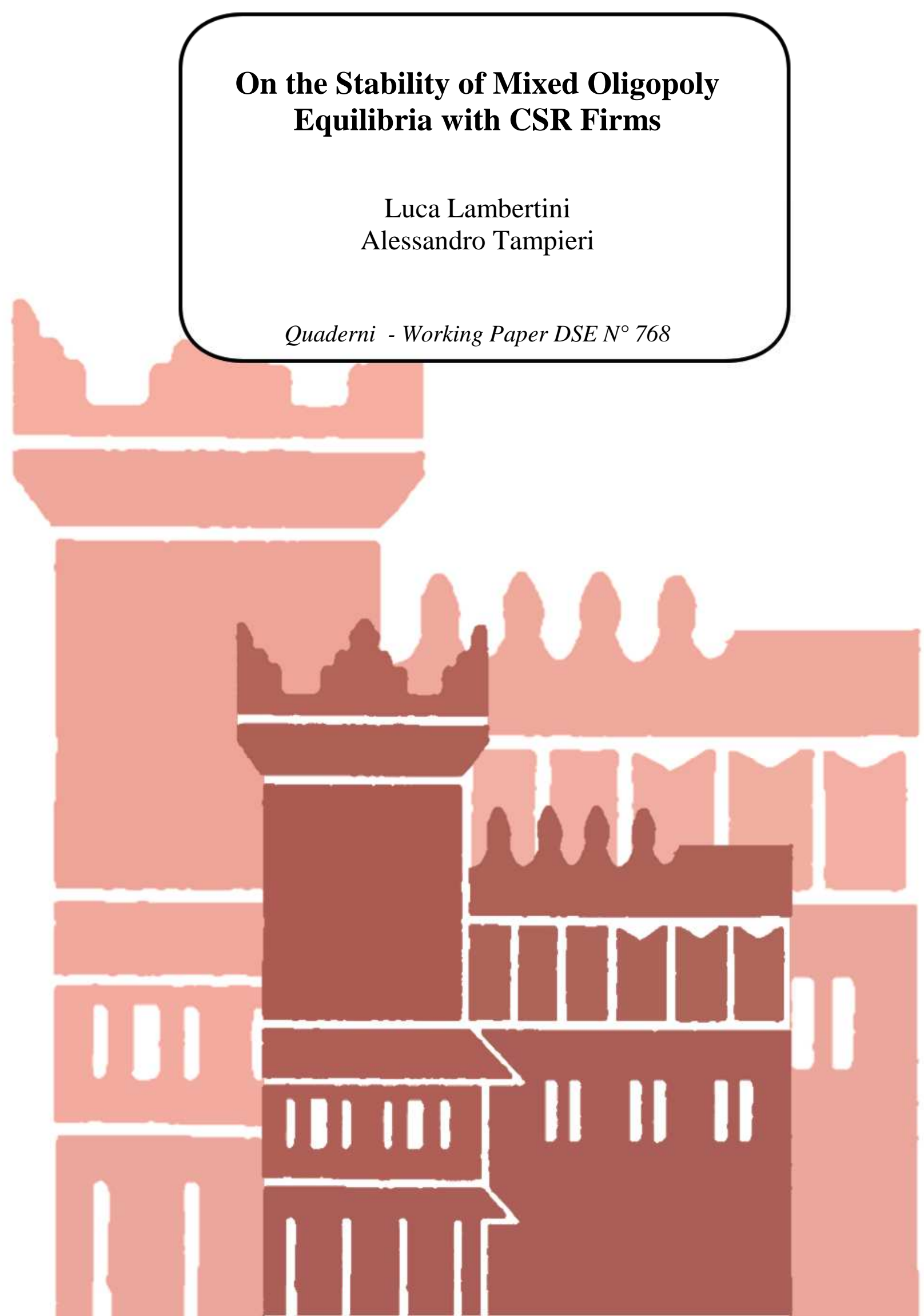




\title{
On the Stability of Mixed Oligopoly Equilibria with CSR Firms
}

\author{
Luca Lambertini ${ }^{\S}, \#$ and Alessandro Tampieri ${ }^{\S}$ \\ $\S$ Department of Economics, University of Bologna \\ Strada Maggiore 45, 40125 Bologna, Italy \\ luca.lambertini@unibo.it; alessandro.tampieri@unibo.it \\ \# ENCORE, University of Amsterdam \\ Roetersstraat 11, WB1018 Amsterdam, The Netherlands
}

July 4, 2011

\begin{abstract}
This paper examines the stability conditions of the equilibria in a market where profit-maximising and CSR firms coexist in the presence of an environmental externality. An equilibrium in mixed duopoly is stable for low impact of productivity on pollution and high CSR sensitivity to consumer surplus. In addition, a mixed oligopoly equilibrium is stable if the number of CSR is sufficiently low.
\end{abstract}

JEL codes: H23, L13, O31.

Keywords: CSR, stability. 


\section{Introduction}

Firms embracing a Corporate Social Responsibility (CSR) regime take into account not only the shareholder interests (profit), but also how the firm decisions affect the agents dealing with the firm (stakeholders), such as employees, business partners, consumers and environment. ${ }^{1}$

The purposes of a firm choosing to follow CSR rules are not necessarily related to environmental or social care. Lambertini and Tampieri (2010) show that, in a Cournot oligopoly where an environmental externality takes place, one firm adopting CSR rules (i.e., internalising its own pollution and caring of consumer surplus) obtains higher profits than the profit-seeking competitors. Hence a firm can decide to be CSR not because moved not by altruistic behaviour but by economic convenience. What the analysis carried by Lambertini and Tampieri (2010) puts aside is the possibility that firms can change their type. In particular, if the CSR firm makes higher profits it is natural to imagine that profit-seeking firms may want to shift to CSR, casting doubts on the stability of the equilibrium.

In this paper we depart from that standpoint by showing the condi-

\footnotetext{
${ }^{1}$ There is not a unique definition of Corporate Social Responsibility. To cite some, for the World Business Council for Sustainable Development in its publication "Making Good Business Sense" (Holme and Watts), "Corporate Social Responsibility is the continuing commitment by business to behave ethically and contribute to economic development while improving the quality of life of the workforce and their families as well as of the local community and society at large" . The CSR definition used by Business for Social Responsibility is "Operating a business in a manner that meets or exceeds the ethical, legal, commercial and public expectations that society has of business" . The European Commission hedges its bets with two definitions wrapped into one: "A concept whereby companies decide voluntarily to contribute to a better society and a cleaner environment. A concept whereby companies integrate social and environmental concerns in their business operations and in their interaction with their stakeholders on a voluntary basis". For a summary, see www.mallenbaker.net/csr/definition.php.
} 
tions for which a mixed oligopoly equilibrium, i.e., an equilibrium where profit-seeking and CSR firms coexist, is stable. We take the same setup of Lambertini and Tampieri (2010), studying a static Cournot oligopoly where production determines a negative environmental externality and one CSR firm is present. Compared to Lambertini and Tampieri (2010), here we consider a pre-market stage where firms can change type both in a duopoly and oligopoly, and we study the conditions such that mixed equilibrium is stable.

Our results show that a low impact of productivity on pollution and a high CSR sensitivity to consumer surplus allows stability of a mixed duopoly. Moreover, in the oligopoly case the mixed oligopoly is stable if number of CSR firms needs to be sufficiently low. Then we show an example of the results of oligopoly through a numerical simulation.

The literature on CSR only recently started developing in the economic literature ${ }^{2}$. One strand identifies CSR with creation of public goods or curtailment of public bads (Bagnoli and Watts, 2003, Kotchen, 2006, Besley and Ghatak, 2010), generally showing that there is a close parallel between CSR so defined and the results obtained by the models of private provision of public goods. Other contributes study the desirability of CSR (Baron, 2001), the role of CSR in selecting motivated agents (Brekke and Nyborg, 2005) or the firm competition in the presence of "green" consumers (Arora and Gangopdhyay, 1995 and Garcia-Gallego and Georgantzís, 2009) or social pressure (Baron, 2009).

The remainder of the paper is organised as follows. Section 2 presents

\footnotetext{
${ }^{2}$ For an overview, see Benabou and Tirole, 2010. For a series of articles on non-market strategy in the form of Corportate Social Responsibility, see the volume 16, issue 3 of the Journal of Economics \& Management Strategy, 2007. For some empirical contribution, Chatterji et al. (2009) analyse the effectiveness of social ratings as a measure of CSR, while Fernández-Kranz and Santaló (2010) test whether Corporate Social Responsibility is driven by strategic considerations by empirically studying the link between competition and firms' social performance.
} 
the framework. Section 3 examines the results in the duopoly case. Section 4 shows the oligopoly case and a numerical example of it. Section 5 concludes.

\section{The model}

We study a static oligopoly market where $n \geq 2$ firms compete à la Cournot. Firms supply a homogeneous good, whose market demand function is $p=$ $a-Q, a$ being a positive constant parameter measuring the reservation price and $Q$ being the sum of all firms' individual output levels $q$. Production takes place at constant returns to scale with a marginal cost $c \in[0, a)$, common to all firms. Throughout the paper, for the sake of simplicity we set $c=0$. The production of the final output goes along with a negative environmental externality $E=g Q$, where $g>0$ represents the marginal polluting intensity of output. Consumer surplus is measured by $C S=Q^{2} / 2$.

There are two possible firm types: "profit-seeking" or "CSR". We denote a generic profit-seeking firm as $p s \in\{1, n\}$, and their profit function as $\pi_{p s}=(p-c) q_{p s}$. We denote a generic CSR firm as $c s r \in\{1, n\}$. According to the "European Union Paper on Corporate Social Responsibility" , CSR companies integrate social and environmental concerns in their business operations. Within the company, socially responsible practices primarily involve employees and relate to issues such as investing in human capital, health and safety, and managing change, while environmentally responsible practices relate mainly to the management of natural resources used in the production. Out of the company, CSR practices involve a wide range of stakeholders: business partners and suppliers, customers, public authorities and local communities, as well as the environment ${ }^{3}$.

Thus we need to assume a specific CSR objective structure. For the environmental concern, we assume that the CSR firm internalises its own

\footnotetext{
${ }^{3}$ See http://www.mallenbaker.net/csr/definition.php.
} 
share of pollution. All the other social concerns can be interpreted in our model as part of consumer surplus, hence we assume that the CSR firm is sensitive to it. Thus the CSR objective function is:

$$
\tilde{\pi}_{c s r}=\pi_{c s r}-g q_{c s r}+\frac{z Q^{2}}{2},
$$

where $z \in[0,1]$ denotes the weight that firm csr assigns to consumer surplus.

The timing is as follows. At stage 1, every firm decides whether to be a profit-seeking or a CSR type. At stage 2, they compete in quantities. The equilibrium concept considered is the subgame perfect equilibrium by backward induction.

\section{Duopoly}

We first examine the case with $n=2$. In the stage 1 , firms 1 and 2 can decide whether to be profit-seeker or CSR, according to the profit of the second stage (Matrix 1).

$$
\begin{aligned}
& 2 \\
& \begin{array}{ll|l|l|}
\multicolumn{1}{c}{} & \multicolumn{1}{c}{\mathrm{PS}} & \multicolumn{1}{c}{\mathrm{CSR}} \\
\cline { 2 - 3 } 1 & \mathrm{PS} & \pi_{p s} ; \pi_{p s} & \pi_{p s}^{M} ; \pi_{c s r}^{M} \\
\cline { 3 - 4 } & \pi_{c s r}^{M} ; \pi_{p s}^{M} & \pi_{c s r} ; \pi_{c s r} \\
\cline { 3 - 4 } & &
\end{array}
\end{aligned}
$$

Matrix 1

The superscript $M$ stands for mixed duopoly (one firm being profit-seeking, the other being CSR). If both firms decide to be profit-seeking, the equilibrium is the PS (i.e., the standard Cournot-Nash) duopoly with $q_{p s}=\frac{a}{3}$ and $\pi_{p s}=\frac{a^{2}}{9}$. If both firms decide to be CSR (CSR duopoly), the quantities in equilibrium are:

$$
q_{c s r}=\frac{a-g}{3-2 z} .
$$


By looking at $q_{c s r}$, note that the sensitivity to consumer surplus $z$ expands the output while the impact of productivity on pollution reduces it. Profits are:

$$
\pi_{c s r}=\frac{(a-g)(a(1-2 z)+2 g)}{(3-2 z)^{2}} .
$$

In the case where one firm chooses the profit-seeking type and the other chooses the CSR type, the market equilibrium is given by:

$$
q_{p s}^{M}=\frac{a(1-z)-g}{3-z},
$$

and

$$
q_{c s r}^{M}=\frac{a(1+z)-2 g}{3-z} .
$$

Through the interplay in the competition stage, $z$ and $g$ appear into the reaction function of the profit-seeking firm affecting its output. Note that an increase of $z$ positively affects the output of the CSR firm and has ambiguous effects on the output of the profit-seeking firm. On the other hand, $g$ decreases both outputs but the effect on the CSR is strong twice as the effect on the profit seeking firm. The profits of the CSR firm are:

$$
\pi_{c s r}^{M}=\frac{(a(1-z)+g)(a(1+z)-2 g)}{(3-z)^{2}},
$$

while the profits of the profit-seeking firm are:

$$
\pi_{p s}^{M}=\frac{(a(1+z)-2 g)^{2}}{(3-z)^{2}} .
$$

The combination of $g$ and $z$ determines the type of duopoly in equilibrium. For the sake of simplicity we will focus the analysis on the case where profits are positive in any possible duopoly type, according to the following lemma.

Lemma 1 The necessary and sufficient condition for positive profits is:

$$
g \in\left(\frac{a(2 z-1)}{2}, \min \left\{\frac{a(1+z)}{2}, a(1-z)\right\}\right)
$$


Proof. $\pi_{c s r}>0$ for all $g \in\left(\frac{a(2 z-1)}{2}, 1\right), \pi_{c s r}^{M}>0$ for all $g \in\left(0, \frac{a(1+z)}{2}\right)$, $\pi_{p s}^{M}>0$ for all $g \in(0, a(1-z))$ and $\pi_{p s}>0$ for all $g \in(0,1)$. Combining these conditions we obtain the lemma.

The following proposition shows which duopoly type occurs depending on the values of $g$ and $z$ (note that $a$ can be normalised to one without changing any result).

Proposition 1 The equilibrium duopoly is:

(i) PS for all

$$
g \in\left(\frac{2 a z}{3}, \min \left\{\frac{a(1+z)}{2}, a(1-z)\right\}\right)
$$

(ii) CSR for all

$$
g \in\left(\frac{a\left(2 z^{3}-9 z^{2}+12 z-3\right)}{2 z^{2}-8 z+9}, \min \left\{\frac{2 a z}{3}, a(1-z)\right\}\right) ;
$$

(iii) mixed for all

$$
g \in\left(\frac{a(2 z-1)}{2}, \min \left\{\frac{a\left(2 z^{3}-9 z^{2}+12 z-3\right)}{2 z^{2}-8 z+9}, a(1-z)\right\}\right) .
$$

Proof. Beginning by (8), we have $\pi_{p s}>\pi_{c s r}^{M}, \pi_{p s}^{M}>\pi_{c s r}$ for all $g>2 a z / 3$, so that the game yields (PS,PS) as the unique equilibrium in dominant strategies. Moreover, $\pi_{p s}>\pi_{c s r}$ for all $g>a(3+2 z) / 6>2 a z / 3$; if instead

$$
g \in\left(\frac{2 a z}{3}, \frac{a(3+2 z)}{6}\right)
$$

the equilibrium is the outcome of a prisoners' dilemma.

In (9) $\pi_{p s}^{M}<\pi_{c s r}$ for all $g>a\left(2 z^{3}-9 z^{2}+12 z-3\right) /\left(2 z^{2}-8 z+9\right)$ and $\pi_{c s r}^{M}>\pi_{p s}>\pi_{c s r}$ for all $g<2 a z / 3$. Given $\pi_{c s r}^{M}>\pi_{p s}>\pi_{c s r}>\pi_{p s}^{M}$ the game yields (CSR,CSR) generated by a prisoners' dilemma.

In (10) we have $\pi_{p s}<\pi_{c s r}^{M}$ for all $g>a(2 z-1) / 2>(5 z-3) / 6$ and $\pi_{p s}^{M}>\pi_{c s r}$ for all $g<a\left(2 z^{3}-9 z^{2}+12 z-3\right) /\left(2 z^{2}-8 z+9\right)$. Here, Matrix 
1 is a chicken game with two asymmetric equilibria along the secondary diagonal.

Figure 1: Duopoly equilibria

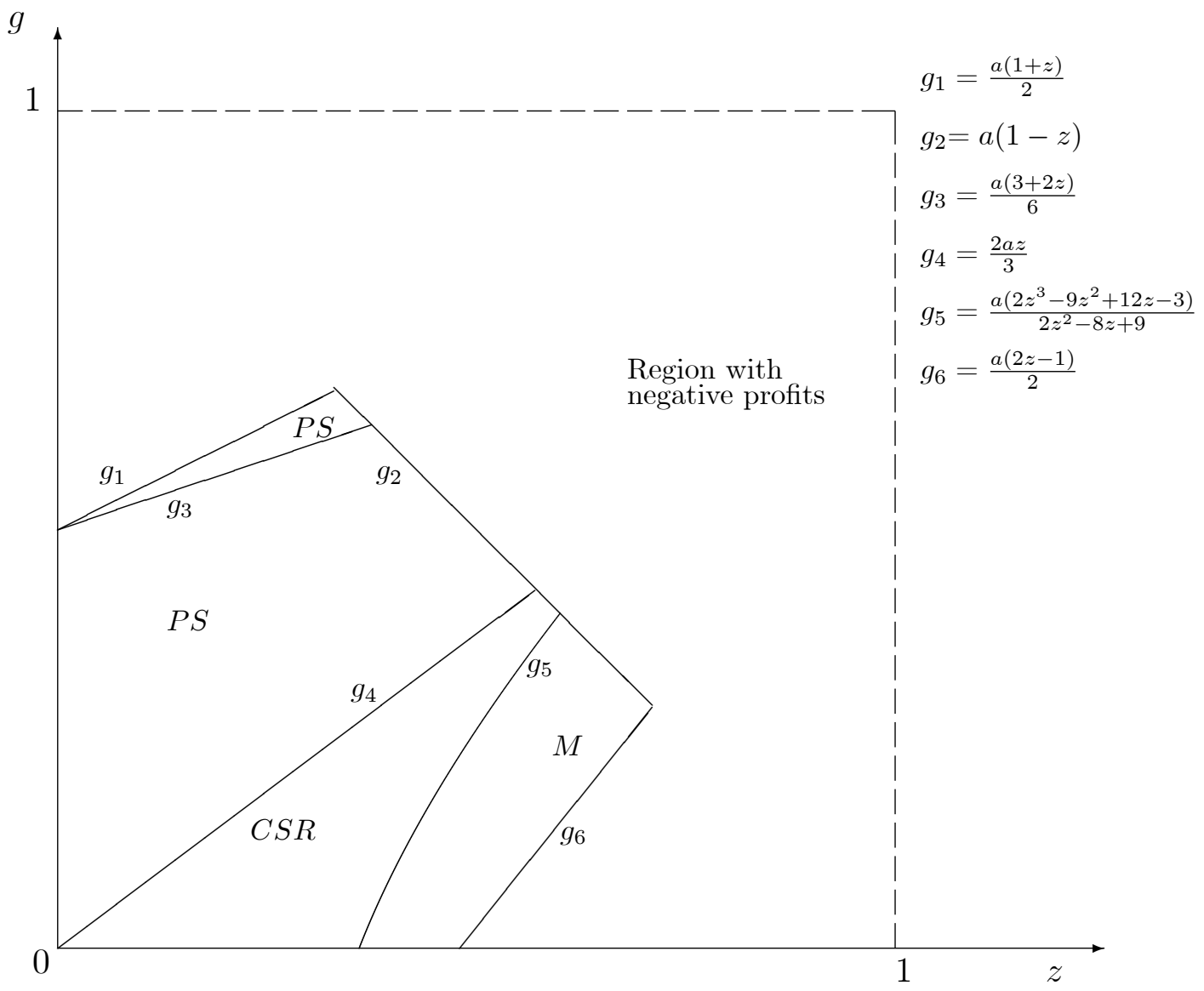

Figure 1 illustrates the combination between the impact of productivity on pollution $g$ and the CSR sensitivity to consumer surplus $z$ allowing a Cournot-Nash, a mixed or a CSR duopoly equilibrium. In the north-west region of Figure 1 (between $g_{1}$ and $g_{3}$ ), the impact of productivity on pollution is quite high, so that a firm being CSR would impose itself a substantial increase in the marginal cost. As a consequence, both firms decide to be profit-seeking. As $g$ becomes lower and the CSR sensitivity to consumer sur- 
plus increases, initially (between $g_{3}$ and $g_{4}$ ) the CSR profit is higher than the profit-seeking profit, but one firm has the incentive to become profit-seeking if the other is CSR, both choose CSR and so the equilibrium is a PS generated by a prisoner's dilemma; then (between $g_{4}$ and $g_{5}$ ) the effect of $z$ becomes stronger, making the output increase compared to the profit-seeking case so that $\pi_{p s}>\pi_{c s r}$, but one firm has the incentive to become CSR if the other is profit-seeking. Therefore both choose to be CSR, resulting in a prisoner's dilemma in a CSR duopoly. Finally (below $g_{5}$ ) the high CSR sensitivity to consumer surplus makes a CSR firm obtain highest profits if the other is profit-seeking and at the same time the profit-seeking firm has no desire to change type, as $\pi_{p s}^{M}>\pi_{c s r}$. Hence the equilibrium is mixed.

\section{Oligopoly}

We analyse now a market with $n>2$. Consider the case where $k \in$ $\{1, . ., n-1\}$ firms are CSR and $n-k$ are profit-seeking, representing a generic mixed oligopoly. In this is case the market equilibrium is given by:

$$
q_{p s}^{k}=\frac{a(1-k z)+g k}{1+n-k z} .
$$

and

$$
q_{c s r}^{k}=\frac{a(1+z(n-k))-g(1+n-k)}{1+n-k z},
$$

where the superscript $k$ stands for "oligopoly with $k$ CSR firms", and $q_{p s}^{M}, q_{c s r}^{M}>$ 0 if

$$
g \in\left(\frac{a(k z-1)}{k}, \frac{a(n z+1-k z)}{n+1-k}\right)
$$

The profits of any individual profit-seeking firm are

$$
\pi_{p s}^{k}=\frac{(a+k(g-a z))^{2}}{(1+n-k z)^{2}}
$$


while the profits of any individual CSR firm are

$$
\pi_{c s r}^{k}=\frac{(a+k(g-a z))(a(1+z(n-k))-g(1+n-k))}{(1+n-k z)^{2}} .
$$

Finally, the conditions of output positivity (14) ensures $\pi_{p s}^{k}, \pi_{c s r}^{k}>0$.

We obtain the stability conditions of the market structure with $k$ CSR firms and $n-k$ profit seeking firms through the requirements for stable cartels (see D'Aspremont et al., 1983 and Donsimoni et al., 1986). A mixed oligopoly with $k$ firms choosing the CSR type and $n-k$ the profit-seeking type is stable if no one CSR firm desires to become profit-seeking (internal stability) and at the same time no one profit-seeking firm desires to shift to CSR (external stability). We denote as

$$
\pi_{p s}^{k-1}=\frac{(a+k(g-a z))^{2}}{(1+n-k z)^{2}}
$$

the profits of one profit-seeking firm if one CSR changes its type. We denote as

$$
\pi_{c s r}^{k+1}=\frac{(a(1-z(k+1))+g(k+1))(a(1+z(n-(k+1)))-g(n-k))}{(1+n-(k+1) z)^{2}},
$$

the profits of one CSR firm if one profit-seeking changes its type. Hence the stability conditions for a market structure with $k$ CSR firms and $n-k$ profit-seeking firms are:

$$
\left\{\begin{array}{l}
\pi_{c s r}^{k}>\pi_{p s}^{k-1}(\text { internal stability) } \\
\pi_{p s}^{k}>\pi_{c s r}^{k+1}(\text { external stability) }
\end{array}\right.
$$

where

$$
\begin{gathered}
\pi_{c s r}^{k}>\pi_{p s}^{k-1} \Rightarrow \frac{(a+k(g-a z))(a(1+z(n-k))-g(1+n-k))}{(1+n-k z)^{2}}> \\
\frac{(a(1-z(k-1))+g(k-1))^{2}}{(1+n-z(k-1))^{2}}
\end{gathered}
$$


and

$$
\begin{gathered}
\pi_{p s}^{k}>\pi_{c s r}^{k+1} \Rightarrow \frac{(a+k(g-a z))^{2}}{(1+n-k z)^{2}}> \\
\frac{(a(1-z(k+1))+g(k+1))(a(1+z(n-(k+1)))-g(n-k))}{(1+n-(k+1) z)^{2}} .
\end{gathered}
$$

The following proposition shows the stability conditions of the mixed oligopoly with $k$ CSR firms and $n-k$ profit-seeking firm.

\section{Proposition 2 If}

$$
\begin{aligned}
& g \in\left(\frac{a\left(n^{2}(k z-1)+\left((z(k-1))^{2}-1\right)(k z-1)+n z(2 k(1-z(k-1))-1)\right)}{1+n-k+k(n+z-k z)^{2}},\right. \\
& \left.\frac{a\left(n^{2}(z(k+1)-1)+\left((k z)^{2}-1\right)(z(k+1)-1)+n z(1+2 k-2 k z(1+k))\right)}{n-k+(k+1)(n-k z)^{2}}\right),
\end{aligned}
$$

$z>\frac{2}{n}$ and $k<\frac{n z}{2}$ then the mixed oligopoly with $k$ firms choosing a CSR type and $n-k$ choosing a profit-seeking type is stable.

Proof. Inequality (20) holds for all

$g \in\left(\frac{a\left(n^{2}(k z-1)+\left((z(k-1))^{2}-1\right)(k z-1)+n z(2 k(1-z(k-1))-1)\right)}{1+n-k+k(n+z-k z)^{2}}, \frac{a n z}{n+1}\right)$,

where $k<\frac{2 z+n}{2 z}$ ensures that

$\frac{a\left(n^{2}(k z-1)+\left((z(k-1))^{2}-1\right)(k z-1)+n z(2 k(1-z(k-1))-1)\right)}{1+n-k+k(n+z-k z)^{2}}<\frac{a n z}{n+1}$.

Since $k \geq 1$, then $\frac{2 z+n}{2 z}>1$, which is always verified for all $\frac{n}{2 z}>0$.

Inequality (21) holds for all

$g<\frac{a\left(n^{2}(z(k+1)-1)+\left((k z)^{2}-1\right)(z(k+1)-1)+n z(1+2 k-2 k z(1+k))\right)}{n-k+(k+1)(n-k z)^{2}}$ 


$$
\vee g>\frac{a n z}{n+1}
$$

where $k<\frac{n z}{2}$ ensures that

$$
\frac{a\left(n^{2}(z(k+1)-1)+\left((k z)^{2}-1\right)(z(k+1)-1)+n z(1+2 k-2 k z(1+k))\right)}{n-k+(k+1)(n-k z)^{2}}<\frac{a n z}{n+1} .
$$

Note that, given $k<\frac{n z}{2}$ and $n>2$, then $\frac{n z}{2}>2$ and thus $z>\frac{4}{n}$. Since $\frac{n z}{2}<\frac{2 z+n}{2 z}, k<\frac{n z}{2}$ is sufficient for $(20)$. The two inequalities hold simultaneously in a range where:

$$
\begin{aligned}
& \frac{a\left(n^{2}(k z-1)+\left((z(k-1))^{2}-1\right)(k z-1)+n z(2 k(1-z(k-1))-1)\right)}{1+n-k+k(n+z-k z)^{2}}< \\
& \frac{a\left(n^{2}(z(k+1)-1)+\left((k z)^{2}-1\right)(z(k+1)-1)+n z(1+2 k-2 k z(1+k))\right)}{n-k+(k+1)(n-k z)^{2}} .
\end{aligned}
$$

The condition $k<\frac{n z}{2}$ is sufficient to ensure that this range exists.

Finally, we verify if $\pi_{p s}^{k}, \pi_{c s r}^{k}>0$, that is if $g$ is within the range described in (14). The sufficient condition is that the stability range is within the positive profit range, i.e.:

$$
\begin{gathered}
\frac{a(n z+1-w z)}{n+1-w}> \\
\frac{a\left(n^{2}(z(k+1)-1)+\left((k z)^{2}-1\right)(z(k+1)-1)+n z(1+2 k-2 k z(1+k))\right)}{n-k+(k+1)(n-k z)^{2}},
\end{gathered}
$$

and

$$
\begin{gathered}
\frac{a\left(n^{2}(k z-1)+\left((z(k-1))^{2}-1\right)(k z-1)+n z(2 k(1-z(k-1))-1)\right)}{1+n-k+k(n+z-k z)^{2}}> \\
\frac{a(w z-1)}{w} .
\end{gathered}
$$


We rearrange (27):

$$
\frac{a(n+1-k z)((n-k z)(n+1-z(k+1))+z-1)}{(n+1-k)\left(n+n^{2}(k+1)-2 n k z(k+1)+k\left(k z^{2}(1+k)-1\right)\right)} .
$$

The numerator is positive since $(n-k z)(n+1-z(k+1))>1$. The denominator is positive for $n^{2}(k+1)-2 n k z(k+1)>0$, which holds for all $k<\frac{n z}{2}$. We rearrange $(28)$ :

$$
\frac{a(n+1-k z)}{w\left(n+1+k\left(n^{2}-1\right)-2 n k z(k-1)+k z^{2}(k-1)^{2}\right)} \text {. }
$$

The denominator is positive for $k\left(n^{2}-1\right)-2 n k z(k-1)>0$, which holds for all $k<\frac{n z}{2}$.

According to Proposition 2, the equilibrium in mixed oligopoly is stable if the number of CSR firms is sufficiently low. We now show an example of mixed oligopoly using appropriate parameter values and solving numerically. We set $n=20, a=10$ and, according to Proposition $2, z=1 / 3$, so that $z>\frac{4}{n}$. Figure 2 shows Proposition 2 in the space $\{k, g\}$ with $k \in(1,19)$. For all $g \in(0,1)$, Proposition 2 holds when $k$ is 2 or 3 .

\section{Figure 2. Interval of $k$ ensuring stability}

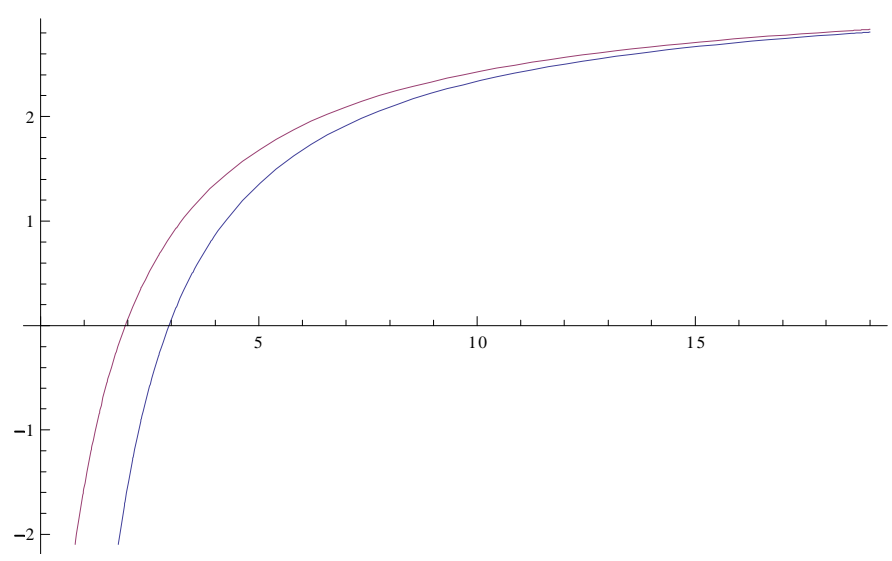


Thus we set $k=3$, ensuring $k<\frac{n z}{2}$ also, and show the system of stability conditions (20)-(21). The mixed oligopoly is stable whenever the system (20)(21) holds, i.e., when the two functions are positive simultaneously. Figure 3 shows that conditions hold in $0.06 \lesssim g \lesssim 0.86$.

Figure 3. Stability conditions for a mixed oligopoly

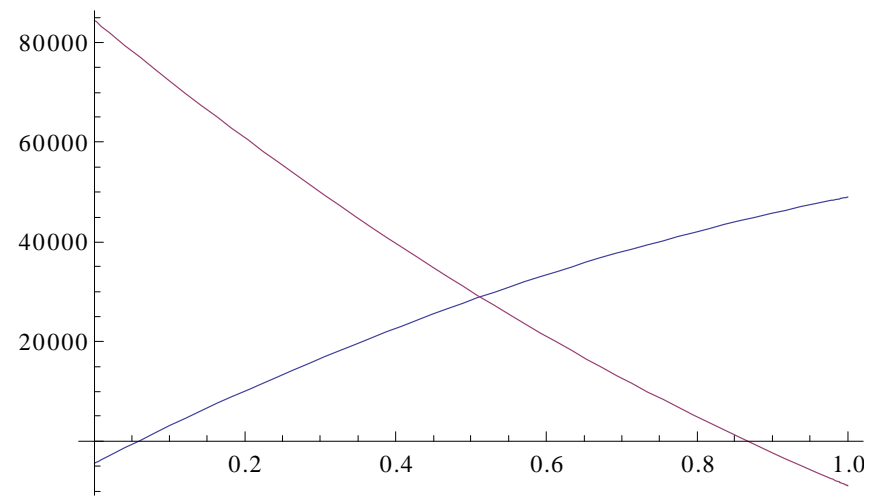

\section{Concluding remarks}

We examined the conditions determining the stability of a mixed oligopoly where profit-seeking and CSR firms coexist in the presence of an environmental externality. An equilibrium in mixed duopoly is stable for low impact of productivity on pollution and high CSR sensitivity to consumer surplus. In addition, a mixed oligopoly equilibrium is stable if the number of CSR is sufficiently low.

\section{References}

[1] Arora, S. and Gangopadhyay, S. 1995. Toward a Theoretical Model of Voluntary Overcompliance. Journal of Economic Behavior and Organization 28: 289-309. 
[2] Baron, D. 2001. Private Politics, Corporate Social Responsibility, and Integrated Strategy. Journal of Economics and Management Strategy 10: $7-45$.

[3] Baron, D.P. and Diermeier, D. (ed.). 2007. Special Issue on Nonmarket Strategy and Social Responsibility. Journal of Economics and Management Strategy, 16, Issue 3.

[4] Baron, D.P. 2009. A Positive Theory of Moral Management, Social Pressure, and Corporate Social Performance. Journal of Economics and Management Strategy, 18: 7-43.

[5] Benabou, R. and Tirole, J. 2010. Individual and Corporate Social Responsibility. Economica 77: 1-19.

[6] Besley, T. and Ghatak, M. 2010. Retailing Public Goods: The Economics of Corporate Social Responsibility. Journal of Public Economics 91: 1645-1663.

[7] Brekke, K. A. and Nyborg, K. 2008. Attracting Responsible employees: Green Production as Labor Market Screening. Resource and Energy Economics 30: 509-526.

[8] Chatterji, A.K., Levine, D. I. and Toffel, M.W. 2009. How Well Do Social Ratings Actually Measure Corporate Social Responsibility? Journal of Economics and Management Strategy, 18: 125-169.

[9] D'Aspremont, C., Jacquemin, A., Gabszewicz, J. J. and Weymark, J. A. 1983. On the Stability of Collusive Price Leadership. The Canadian Journal of Economics 16: 17-25.

[10] Donsimoni, M. P., Economides, N. S. and Polemarchakis, H. M. 1986. Stable Cartels. International Economic Review 27: 317-327. 
[11] Fernández-Kranz D. and Santaló, J. 2010. When Necessity Becomes a Virtue: The Effect of Product Market Competition on Corporate Social Responsibility. Journal of Economics and Management Strategy, 19: 453-487.

[12] Garcia-Gallego, A. and Georgantzís, N. 2009. Market Effects of Changes in Consumers' Social Responsibility. Journal of Economics and Management Strategy, 19: 453-487.

[13] Kotchen, M. J. 2006. Green Markets and Private Provision of Public Goods. Journal of Political Economy 114: 816-845.

[14] Lambertini, L. and Tampieri, A. 2010. Corporate Social Responsibility in a Mixed Oligopoly. Department of Economics, University of Bologna Working paper $\mathbf{7 2 3}$. 


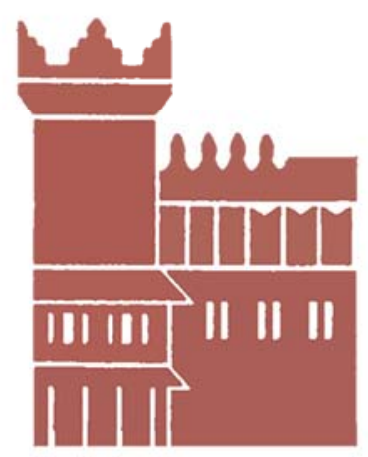

Alma Mater Studiorum - Università di Bologna DEPARTMENT OF ECONOMICS

Strada Maggiore 45

40125 Bologna - Italy

Tel. +39051 2092604

Fax +390512092664

http://www.dse.unibo.it 